\title{
Making the cut: analytical and empirical bioethics
}

This issue of the journal includes papers across both analytical and empirical schools within bioethics.

In his feature article, 'The kindest cut? Surgical castration, sex offenders and coercive offers', John McMillan asks whether surgical castration can be ethically provided as medical treatment for sex offenders (see page 583, Editor's choice). While surgical castration has previously been available in a number of European countries, in recent years it has only been available in the Czech Republic and in Germany. The European Committee for the Prevention of Torture has attacked the Czech and German governments for engaging in degrading treatments. McMillan focuses on the nature of the relationship between psychiatrist and the detainee. Is the option of surgical castration (with the chance of earlier release) a non-coercive 'offer', or is the option of non-castration (with the likelihood of continued detention) a coercive threat? For McMillan, the nature of the intent is important, but he argues that the Czech and German approaches to surgical castration are not necessarily coercive, and can be a component of ethically praiseworthy self-transformation.

Responding to McMillan, Alan Wertheimer and Franklin Miller focus on the question of coercion (see page 592). They argue that the offer of castration is only coercive if psychiatrists or the state threaten to violate sex-offenders' rights, or forego an obligation to the prisoner if he declines castration. On their view, such offers are not coercive, though they note that this does not settle the key ethical questions.

Jesper Ryberg and Thomas Petersen, by contrast, argue both that offers can be coercive and that coercive offers could be morally legitimate - where there is a significant societal benefit (see page 593). They suggest that lifelong detention (in order to protect others within society) represents a more severe example of force or coercion than surgical castration. If the former is justified, the latter may be too. Elizabeth Shaw, disagrees with Ryberg and Petersen (see page 594). On her view, medical interventions to alter someone's body or mind are more worrying than imprisonment. They therefore warrant greater scrutiny.
Finally, William Winslade provides a fascinating real world application of McMillan's analysis (see page 591). He argues that the Texan voluntary surgical castration statute fulfills McMillan's criteria for ethically permissible surgical castration. He also describes in detail, through a case study, the way in which castration can permit transformation of a live gone awry. The possibility of radical change in an individual is the real benefit of surgical castration, but it also illuminates the reason why coerced castration would be so troublesome.

"Accustom yourself to believe that death is nothing to us". ${ }^{1}$ So wrote the Greek philosopher Epicurus in a letter in the third century BCE. More than two thousand years later, American philosopher James Stacey Taylor has taken up where Epicurus left off in his 2012 book "Death, posthumous harm and bioethics". ${ }^{2}$ Taylor, in our second 'Author meets critics' feature for the journal, provocatively argues that death is not a harm to the individual who dies, and that the dead can be neither harmed nor wronged (see page 636). He suggests that such a view has significant implications for debates in bioethics.

Frederik Kaufman and Stephen Blatti reject Taylor's metaphysical argument. Kaufman defends a deprivation account of the harm of death (see page 639), while Stephen Blatti argues that the harm of death can be experienced (before death) (see page 640). Walter Glannon and Timothy Wilkinson examine the implications of Taylor's arguments for organ donation. Glannon claims, contra Taylor, that events after death (for example organ conscription) could violate an individual's rights and wrong them (see page 637). However, he also suggests that the metaphysical claims of Epicurus and Taylor do not necessarily yield ethical conclusions. Organ conscription would threaten public trust in organ transplantation, and undermine support by the living for donation after death. Wilkinson, in contrast, finds Taylor's emphasis on the living helpful for presumed consent policies (see page 638). Rather than focusing on whether particular policies would lead or more or fewer post-mortem mistakes, we should develop an appropriate procedure for recording people's wishes about donation and then accord them due weight.

Elsewhere in this issue there are some interesting empirical studies looking at attitudes to physician assisted suicide and abortion in Africa, conscientious objection amongst medical students in Norway, and organ retention after autopsy in Japan. These are accompanied by a paper by German ethicists Sabine Salloch, Jochen Vollmann and Jan Schildmann, who critically analyse the role of empirical studies like these in normative argument (see page 597).

Empirical studies could be used in a variety of different ways. For example, the majority of lay Togolese surveyed by Kpanake and colleagues judged physician assisted suicide to be acceptable in at least some circumstances (see page 621). This is the first study of public opinion towards physician assisted suicide in Africa, and might be thought to support more liberal policies in that continent. However, Salloch et al agree with other philosophers that we should avoid the temptation to do 'ethics by opinion poll'. This is partly for meta-ethical reasons; Hume long ago cautioned about deriving an ought from an is. Salloch et al also point to important methodological concerns for this use of attitudinal research. As noted by Kpanake and colleagues, their sample of the Togolese public constituted only those living in the capital city who happened to be sampled and were willing to be surveyed. Their answers to theoretical vignettes might be different from their views about actual cases. Furthermore, health professionals in their survey were largely opposed to physician assisted suicide. The question of whose views should be followed does not emerge from empirical research, but requires further analysis and argument.

A second alternative role for empirical studies in bioethics is explicitly linked to a particular ethical framework. For example, Salloch et al refer to the possible role of empirical research in preference utilitarian analyses of issues in medical ethics. The paper by Wonkam and colleagues from Cameroon could be used in this way (see page 615). Cameroon has a relatively high rate of a genetic blood 
disorder, sickle cell disease (SCD), which causes repeated painful attacks and a number of serious health complications. In Africa, many affected patients die in early childhood, and there is no universal medical coverage in Cameroon. Wonkam and colleagues have previously shown a high rate of support for prenatal diagnosis and abortion among parents of children affected by SCD. Their new study provides additional data from patients with SCD. Ninety percent of adult patients with SCD in Cameroon would consider pre-natal diagnosis, and 40\% would consider termination of pregnancy. The preferences of these individuals might be thought to be particularly important on some accounts of (rational) preference utilitarianism, since these individuals are likely to have a high level of understanding about the condition and its impact upon daily life.

Finally, Salloch et al discuss the important practical role of empirical research in bioethics, which is (at least partly) independent of debates about ethical theory and meta-ethical qualms. Explorative empirical research can help to identify new questions and problems as well as the ways that practitioners have developed to address them. For example, Tsujimora-Ito and colleagues identify the difficult problems that surround organ and tissue retention after forensic autopsy in Japan (see page 603). Empirical research can also identify some likely barriers to particular policies. The high rate of objection to physician assisted suicide amongst medical practitioners in Togo might be a problem if this were to be permitted there. Nordstrand and colleagues report high rates of conscientious objection amongst medical students in Norway (see page 609). Norwegian students would personally refuse to take part in a range of medical procedures, including euthanasia, but also abortion and male circumcision. Again, data like this is relevant to debates about specific procedures, but also to wider questions around the response to conscientious objection.

As the papers in this issue make clear, high quality analytical research and high quality empirical research are both required if we are to cut the Gordian knot and make progress in medical ethics. Analytical research, like John McMillan's feature article and James Stacey Taylor's book, are strengthened by drawing on empirical research and real cases. Empirical papers such as the ones summarised above, require further ethical analysis, before they can be applied to debate.

\section{REFERENCES}

1 Epicurus. Letter to Menoeceus. http://classics.mit.edu/ Epicurus/menoec.html (accessed 22 Jul 2014)

2 Taylor JS. Death, Posthumous Harm, and Bioethics. New York: Routledge, 2012. 